\title{
Enhanced Intercellular Delivery of cRGD-siRNA Conjugates by an Additional Oligospermine Modification
}

\author{
Kosuke Nakamoto, ${ }^{\dagger}$ Yukihiro Akao, ${ }^{\dagger}$ Yasuhiro Furuichi, ${ }^{\S}$ and Yoshihito Ueno ${ }^{*}, \dagger, \|, \perp_{(}$ \\ ${ }^{\dagger}$ United Graduate School of Agricultural Science, ${ }^{\ddagger}$ United Graduate School of Drug Discovery and Medical Information Sciences, \\ and "Faculty of Applied Biological Sciences, Gifu University, 1-1 Yanagido, Gifu 501-1193, Japan \\ ${ }^{\perp}$ Center of Highly Advanced Integration of Nano and Life Sciences, Gifu University (G-CHAIN), 1-1 Yanagido, Gifu 501-1193, \\ Japan \\ ${ }^{\S}$ GeneCare Research Institute Co., Ltd., 19-2 Kajiwara, Kamakura 247-0063, Japan
}

Supporting Information

ABSTRACT: Small interfering RNA (siRNA), consisting a 21-mer duplex molecule, is often modified by conjugation with specific ligands to enhance its capacity for tissue-specific delivery. However, these attempts are hampered by the low permeability of negatively charged RNA molecules to enter the cell membrane. In this study, we designed and synthesized siRNA conjugates modified with cationic oligospermine and cyclic RGD (cRGD) to overcome the lowmembrane permeability of siRNA. The siRNA conjugate, which contains 15 spermines and a cRGD peptide, showed sufficient gene-silencing activity at 250 $\mathrm{nM}$ final concentration without a transfection reagent. Under these conditions, the cationic oligospermine and cRGD-siRNA conjugate did not show any cytotoxicity.

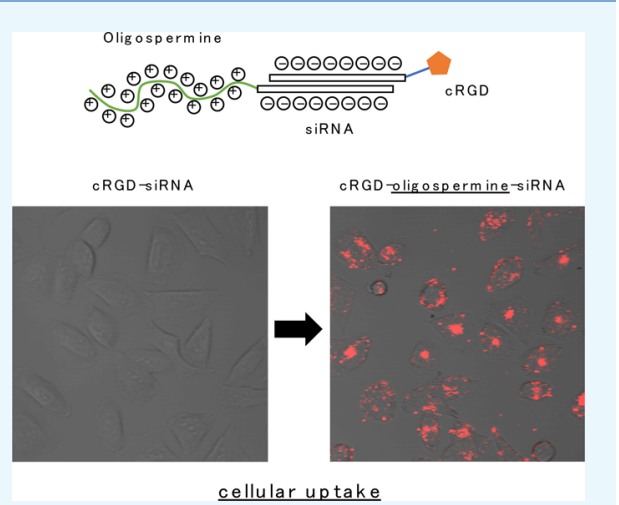

\section{INTRODUCTION}

Oligonucleotide $(\mathrm{ON})$ therapeutics, using rationally designed antisense oligonucleotides (ASONs) or small interfering RNAs (siRNAs), are promising candidates for a treatment of unmet medical needs, which could not be covered by conventional lowmolecular-weight drugs. ${ }^{1,2}$ However, these ONs, especially double-stranded siRNAs, have relatively high molecular weights and negative charges derived from a phosphodiester backbone. As a result, they can hardly penetrate the negatively charged cell membrane. ${ }^{3}$ Furthermore, the ASON and siRNA composed of natural nucleosides do not exhibit tissue specificity. Therefore, the development of a target tissue-specific drug delivery system is crucial for the use of ASON or siRNA as a drug. To date, numerous chemical approaches have been reported to overcome the low membrane permeability of siRNA. ${ }^{4,5}$ Among them, a targeted tissue-specific ligand-siRNA conjugate is one promising strategy for siRNA delivery into specific cells. ${ }^{6-15}$ In particular, siRNAs conjugated with triantennary $\mathrm{N}$-acetylgalactosamine (GalNAc), which has a high binding affinity to the asialoglycoprotein receptor (ASGR), have shown efficient genesilencing activity in vivo, and clinical and preclinical trials are ongoing. ${ }^{13-15}$ Because ASGR is highly expressed in hepatocytes and shows rapid internalization and recycling, GalNAc-siRNA conjugates bound to ASGR are readily incorporated into cells and exhibit sufficient gene-silencing activity at low concentrations. However, unfortunately, the development of other type of ligand-siRNA conjugates has not been successful because of the low membrane permeability of RNA molecules. Although the development of alternative ligand-siRNA conjugates is required to expand deliverable tissues, no comparable ligandreceptor systems, similar to GalNAc-ASGR, are yet to be established. Therefore, to develop ligand-siRNA conjugates that target receptors other than ASGR, a new approach which improves potentially low cell membrane permeability of siRNA conjugate is needed.

In in vitro studies using cultured cells, it was demonstrated that cationic oligospermine conjugates neutralized the negative charge of siRNAs derived from their phosphodiester backbones, resulting in improved thermal stability, nuclease resistance, and cell membrane permeability. ${ }^{16-19}$ Although oligosperminesiRNA and AON conjugates have been synthesized and successfully transfected in vitro, ${ }^{20}$ tissue-specific delivery of oligospermine-siRNA or AON conjugates has not been achieved because of spermine's lack of tissue specificity. Further, more than 20 spermine molecules must be conjugated to one siRNA to provide sufficient cell permeability, which sometimes causes cytotoxicity. ${ }^{18}$ Alternatively, the cyclic RGD (cRGD) peptide has a high binding affinity for integrin $\alpha_{\mathrm{V}} \beta 3$, which is overexpressed on the surface of various tumor cells. ${ }^{21}$ cRGDsiRNA conjugates have been successfully transfected in vitro and in vivo by several research groups. ${ }^{22,23}$

Received: April 29, 2018

Accepted: June 7, 2018

Published: July 24, 2018 
On the basis of these reports, we designed and synthesized siRNA conjugates containing both the cationic oligospermine and the tumor-targeting cRGD peptide (Figure 1). We

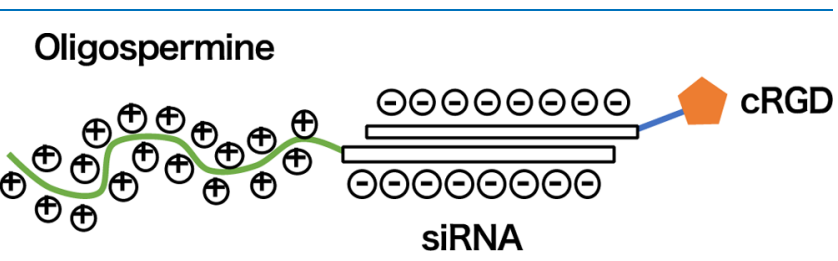

Figure 1. Schematic illustration of cationic oligospermine and cRGDsiRNA conjugates.

postulated that the cationic oligospermine modification of the cRGD-siRNA would increase its membrane permeability, thus enhancing the tumor cell-specific delivery. Furthermore, we postulated that the oligospermine and cRGD-peptide would work synergistically. As such, the amount of spermine to be incorporated into the siRNA could be reduced, thus reducing oligospermine-induced cytotoxicity.

\section{RESULTS AND DISCUSSION}

Synthesis of ON Conjugates. We designed and synthesized siRNA conjugates modified by both oligospermine and cRGD at the $3^{\prime}$-termini of the sense and antisense strands, respectively. RecQL1-siRNA, which silences the RecQL1 mRNA encoding RecQL1 DNA helicase, was chosen as a model siRNA. Futami and colleagues have previously shown that gene silencing of RecQL1 helicase by RecQL1-siRNA results in the following: (1) inhibits DNA repair in replicating cells, (2) induces mitotic catastrophes at the checkpoints of negative tumor cells, and (3) causes mitotic death in the tumor cell specifically. ${ }^{24,25}$ It was also reported that oligospermine conjugation at the antisense (guide) strand of the siRNA reduces the siRNA silencing activity greater than the sense (passenger) strand. ${ }^{19}$ Thus, we introduced the oligospermine at the $3^{\prime}$ end of the sense (passenger) strand and cRGD at that of the antisense (guide) strand, respectively (Figure 2A,B). To improve nuclease resistance and silencing activities of the siRNAs, the 2 -hydroxyl group of some pyrimidine nucleotides was modified by a methyl group (Table 1). The $2^{\prime}$-O methylations are known to reduce immunogenicity of siRNAs and to suppress the innate immune response. ${ }^{26}$

Incorporation of cRGD peptide into the antisense strand was carried out by a postsynthetic modification method (Scheme 1). Briefly, single-stranded RNA (ssRNA) 6, which has a reactive amino moiety at the $3^{\prime}$ end of the strand, was synthesized using an amino-modified controlled pore glass (Scheme S1). Subsequently, 6 was reacted with $N$-(6-maleimidocaproyloxy)succinimide (EMCS) in a phosphate buffer $(\mathrm{pH}=7.4)$ at $37^{\circ} \mathrm{C}$ to give a maleimide-modified ssRNA 8. A thiol-containing cRGD peptide (cRGDfC) was conjugated to 8 via a thiolmaleimide Michael addition reaction to produce cRGD conjugate 1. To assess the cellular uptake of the conjugate, a Cy3-labeled cRGD conjugate $\mathbf{2}$ was also synthesized by a similar procedure. Product purification was performed by reversedphase high-performance liquid chromatography (RP-HPLC), and the structures of the synthesized ONs were confirmed by matrix-assisted laser desorption ionization time-of-flight/mass spectrometry (Table S2). The cationic oligospermine conjugates 3-5 were synthesized according to the procedure previously reported using a spermine amidite. ${ }^{27}$ To determine the number of spermine required for cellular uptake and examine the effects of the $\mathrm{N} / \mathrm{P}$ ratio on cellular uptake, we synthesized three oligospermine conjugates with different amounts of spermine modifications. Each ssRNA conjugates were annealed to complementary RNA to form the siRNA conjugates with the oligospermine and cRGD.

Cellular Uptake Test. Cellular uptakes of Cy3-labeled siRNA conjugates were evaluated using confocal laser microscopy. Human melanoma A2058 cells were incubated with $200 \mathrm{nM}$ of each Cy3-labeled siRNA conjugates in serumfree medium. After a $3 \mathrm{~h}$ incubation, accumulations of Cy3labeled siRNA conjugates in the cells were visualized by confocal laser microscopy (Figure 3). In the siQL1[S10/RGD] and siQL1[S15/RGD] RNAs, which were modified by spermine, the accumulation of $\mathrm{Cy} 3$ fluorescence signal was detected. However, no fluorescence signal was seen in the unmodified spermine conjugate, siQL1[RGD]. The fluorescence intensity in the cell was dependent on the number of spermine molecules

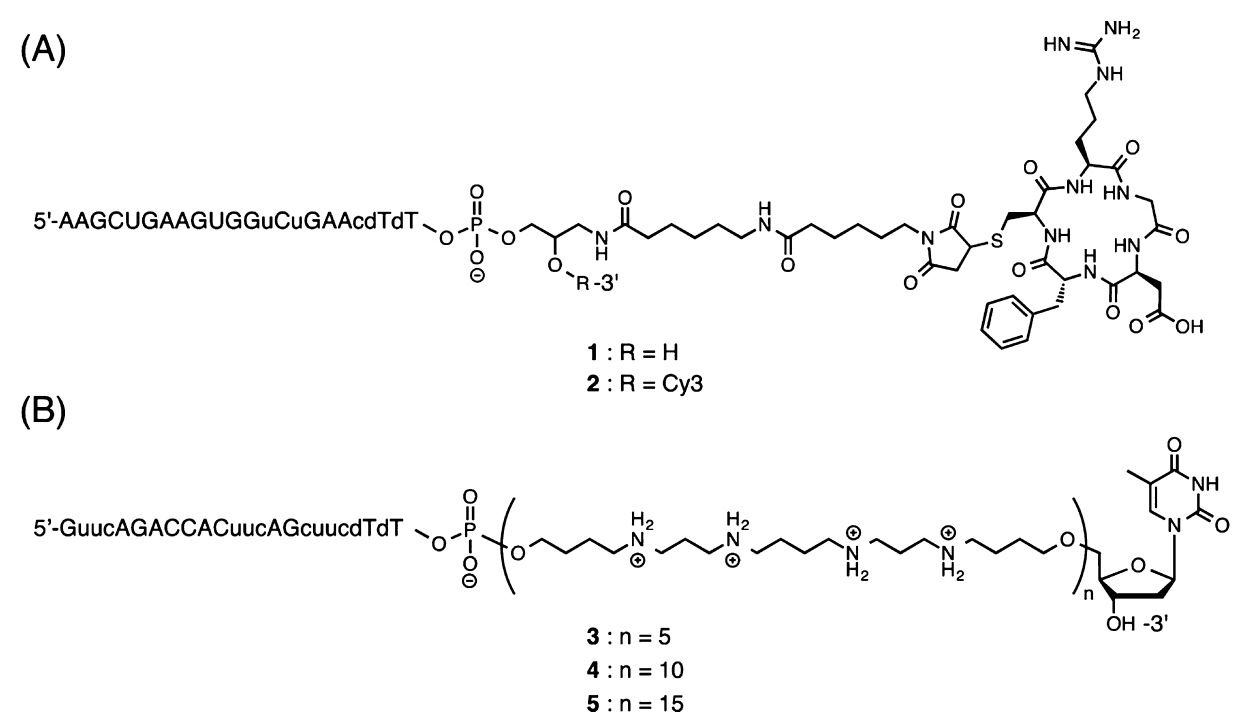

Figure 2. (A) Structures of antisense RNAs conjugated to cRGD. (B) Structures of sense RNAs conjugated to cationic oligospermine. Small letters indicate $2^{\prime}$-O-methyl RNA and dT indicates 2 '-deoxythymidine. 
Table 1. Sequences of siRNAs, N/P Ratio

\begin{tabular}{|c|c|c|c|}
\hline name & $\mathrm{S} / \mathrm{AS}^{a}$ & sequence $\left(5^{\prime}-3^{\prime}\right)^{b}$ & $\mathrm{~N} / \mathrm{P}$ \\
\hline \multirow[t]{2}{*}{ siQL1 } & $S$ & GuucAGACCACuucAGcuudTdT & \\
\hline & AS & AAGCUGAAGUGGuCuGAAcdTdT & \\
\hline \multirow[t]{2}{*}{$\operatorname{siQL1}[\mathrm{RGD}]$} & $S$ & GuucAGACCACuucAGcuudTdT & \\
\hline & AS & AAGCUGAAGUGGuCuGAAcdTdT-RGD & \\
\hline \multirow[t]{2}{*}{ siQL1[S5/RGD] } & $S$ & GuucAGACCACuucAGcuudTdT-S $\mathrm{S}_{5}$-dT & 0.42 \\
\hline & AS & AAGCUGAAGUGGuCuGAAcdTdT-RGD & \\
\hline \multirow[t]{2}{*}{$\operatorname{siQL1}[\mathrm{S} 10 / \mathrm{RGD}]$} & $S$ & GuucAGACCACuucAGcuudTdT-S $S_{10}$-dT & 0.77 \\
\hline & AS & AAGCUGAAGUGGuCuGAAcdTdT-RGD & \\
\hline \multirow[t]{2}{*}{$\operatorname{siQL1}[\mathrm{S} 15 / \mathrm{RGD}]$} & $S$ & GuucAGACCACuucAGcuudTdT-S ${ }_{15}$-dT & 1.03 \\
\hline & AS & AAGCUGAAGUGGuCuGAAcdTdT-RGD & \\
\hline \multirow[t]{2}{*}{$\operatorname{siQL1}[S 15]$} & $S$ & GuucAGACCACuucAGcuudTdT-S ${ }_{15}$-dT & 1.05 \\
\hline & AS & AAGCUGAAGUGGuCuGAAcdTdT & \\
\hline \multirow[t]{2}{*}{ Cy3-siQL1 } & $S$ & GuucAGACCACuucAGcuudTdT & \\
\hline & AS & AAGCUGAAGUGGuCuGAAcdTdT-Cy3 & \\
\hline \multirow[t]{2}{*}{ Cy3-siQL1[RGD] } & $\mathrm{S}$ & GuucAGACCACuucAGcuudTdT & \\
\hline & AS & AAGCUGAAGUGGuCuGAAcdTdT-RGD-Cy3 & \\
\hline \multirow[t]{2}{*}{ Cy3-siQL1[S5/RGD] } & S & GuucAGACCACuucAGcuudTdT-S S $^{-} \mathrm{dT}$ & 0.41 \\
\hline & AS & AAGCUGAAGUGGuCuGAAcdTdT-RGD-Cy3 & \\
\hline \multirow[t]{2}{*}{ Cy3-siQL1[S10/RGD] } & $S$ & GuucAGACCACuucAGcuudTdT-S ${ }_{10}$-dT & 0.75 \\
\hline & AS & AAGCUGAAGUGGuCuGAAcdTdT-RGD-Cy3 & \\
\hline \multirow[t]{2}{*}{ Cy3-siQL1[S15/RGD] } & $\mathrm{S}$ & GuucAGACCACuucAGcuudTdT-S $_{15}$-dT & 1.02 \\
\hline & AS & AAGCUGAAGUGGuCuGAAcdTdT-RGD-Cy3 & \\
\hline \multirow[t]{2}{*}{ Cy3-siQL1[S15] } & $S$ & GuucAGACCACuucAGcuudTdT-S ${ }_{15}$-dT & 1.03 \\
\hline & AS & AAGCUGAAGUGGuCuGAAcdTdT-Cy3 & \\
\hline
\end{tabular}

Scheme 1. Synthesis of cRGD Conjugates; (a) EMCS, in a Phosphate Buffer (pH 7.4), Room Temperature, Overnight and (b) c(RGDfC), in $0.1 \mathrm{M}$ triethylammonium acetate (TEAA), $50 \% \mathrm{MeCN}$ aq, Room Temperature, Overnight

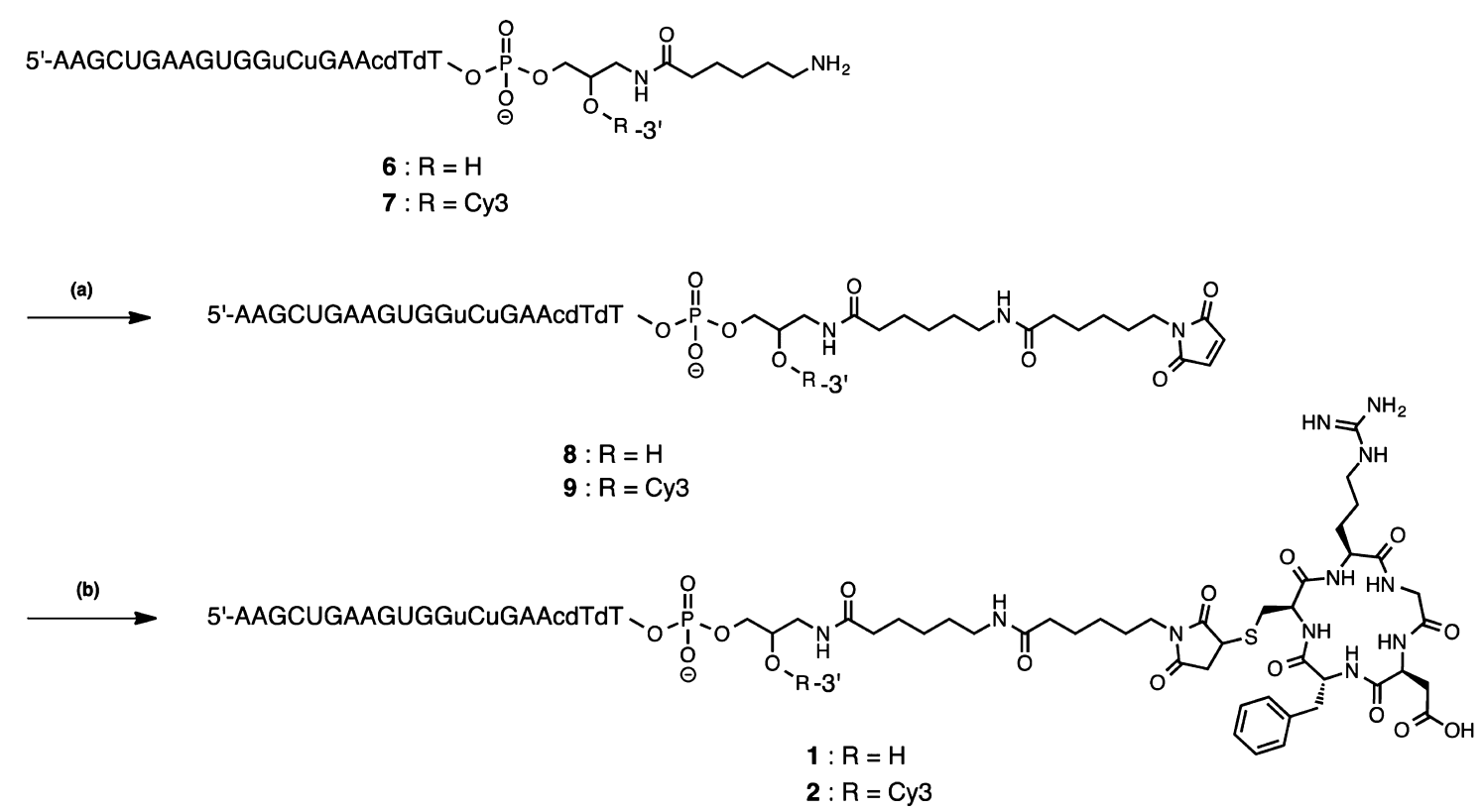

conjugated to RNA. The strongest fluorescence intensity was observed when the siQL1[S15/RGD] was used. These results indicate that the cationic oligospermine addition to cRGDsiRNA conjugates promoted cellular uptake. Furthermore, because the fluorescence intensity in A2058 cells was significantly lower in the cRGD-unmodified siQL1[S15], it is conceivable that the synergistic work of $\mathrm{CRGD}$ and cationic oligospermine may be crucial for the cellular uptake of siRNA conjugates.
Gene-Silencing Activities. To evaluate the RNA interference (RNAi) activity of the cRGD and oligospermine-modified siRNAs, we assessed the gene-silencing activities of each siRNA conjugate in the presence of the transfection reagent Lipofectamine. Each siRNA conjugate was mixed with Lipofectamine RNAiMAX and transfected into HeLa cells at $20 \mathrm{nM}$ final concentration. The relative expression levels of RecQL1 mRNA were measured by RT-qPCR. In Figure 4A, all siRNA conjugates showed greater gene-silencing activity than the unmodified 


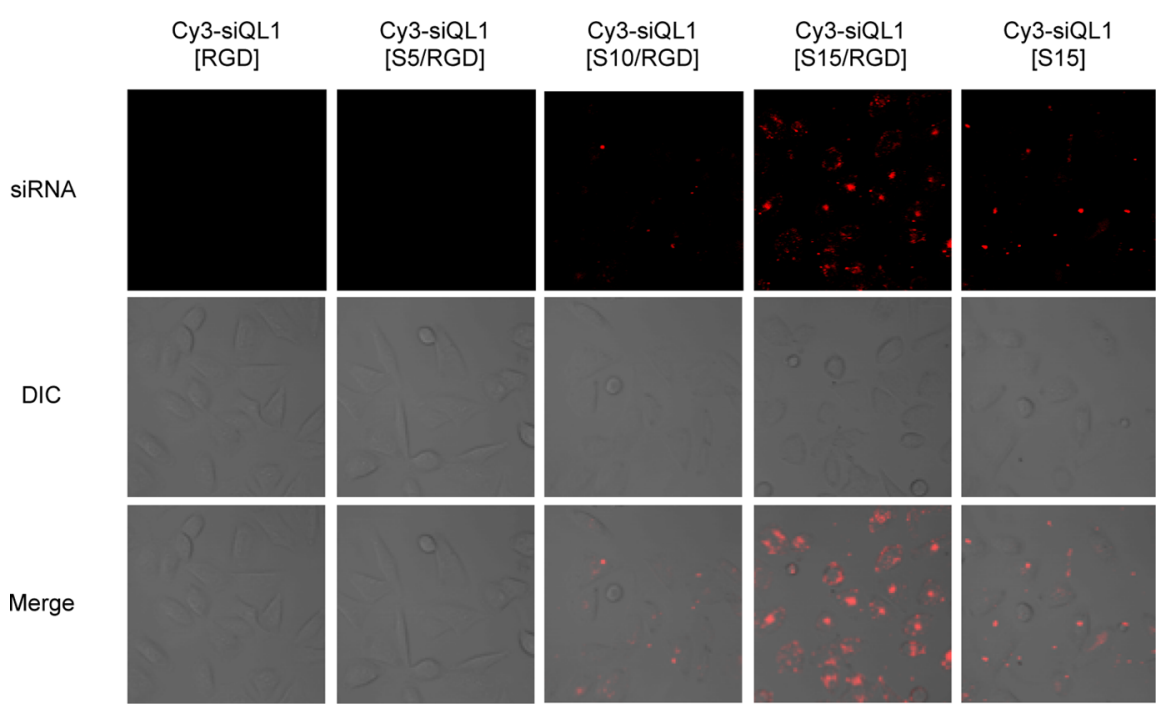

Figure 3. Transfection reagent-free cellular uptake of Cy3-labeled siRNA heteroconjugates in vitro. A2058 cells were treated with $200 \mathrm{nM}$ of Cy3labeled siRNA conjugates. After a $3 \mathrm{~h}$ incubation, Cy3-labeled siRNA conjugates were visualized by confocal laser microscopy.

(A)

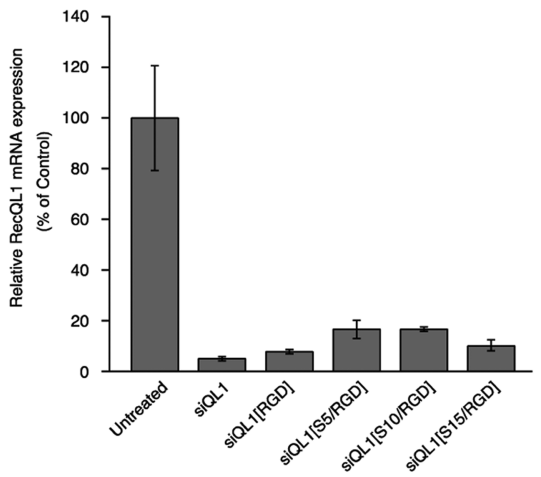

(D)

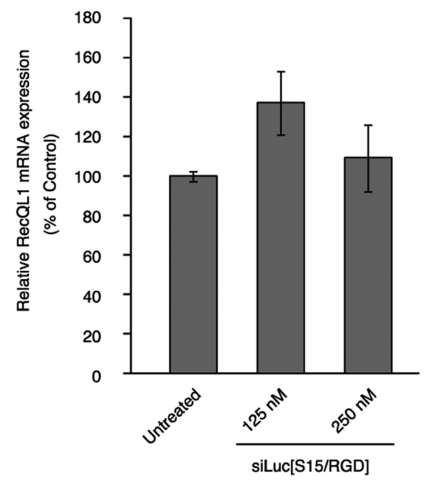

(B)

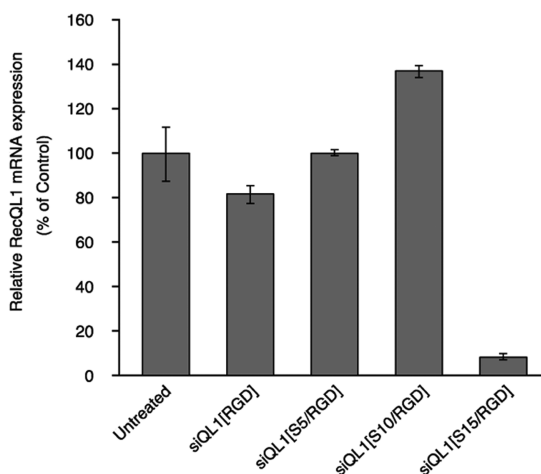

(C)

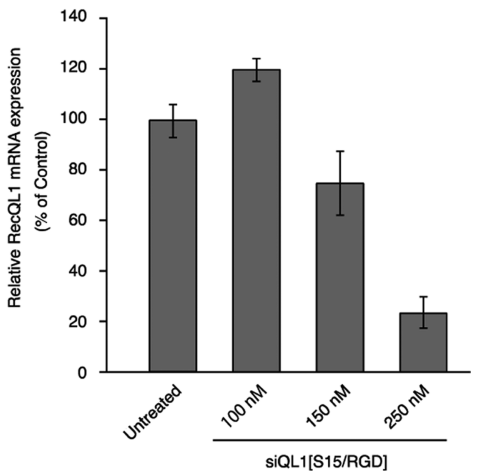

(E)

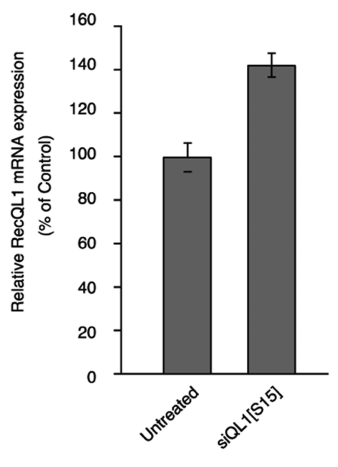

(F)

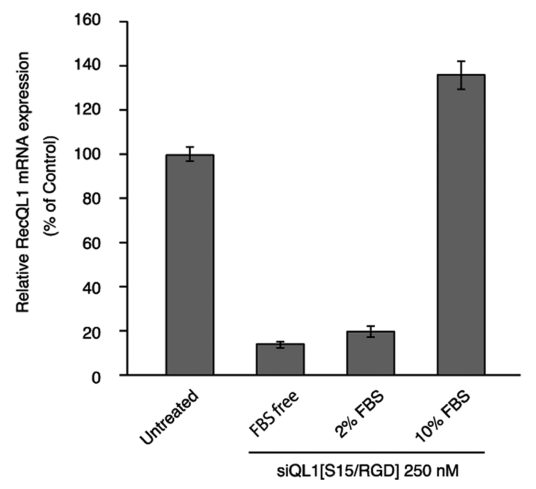

Figure 4. Effect of RECQL1-siRNA conjugates on the expression of HeLa cell RECQL1 mRNA. (A) siRNA (20 nM) conjugates were transfected using Lipofecatamine RNAiMAX. (B) HeLa cells were transfected with $250 \mathrm{nM}$ of siRNA conjugates without a transfection reagent. (C) Cells were transfected with 100-250 nM of siQL1[S15/RGD] without a transfection reagent. (D) Cells were transfected with 125 and $250 \mathrm{nM}$ of siLuc[S15/ RGD] without a transfection reagent. (E) Cells were transfected with $250 \mathrm{nM}$ of siQL1[S15] without a transfection reagent. (F) siQL1[S15/RGD] were transfected without a transfection reagent in the absence or presence of FBS.

siQL1. These data indicated that the modification of siRNA by cRGD and oligospermine does not disrupt the formation of the RNA-induced silencing complex and target mRNA recognition.

We then evaluated the gene-silencing activities of siRNA conjugates without transfection reagent under serum-free conditions. As shown in Figure 4B,C, only siQL1[S15/RGD] showed strong gene-silencing activity at $150-250 \mathrm{nM}$. The result indicates that the cationic oligospermine modification improved the cell membrane permeability of cRGD-siRNA conjugates. In addition, it was found that at least 15 spermine 
modifications $(\mathrm{N} / \mathrm{P}=1.02)$ were needed for efficient genesilencing activity. Previously, it was reported that oligospermine-siRNA conjugates required more than 20 spermine modifications $(\mathrm{N} / \mathrm{P}=1.33)$ for efficient gene-silencing activity without a transfection reagent. ${ }^{20}$ Thus, the cRGD peptide addition to siRNA reduces the required number of oligospermine molecules, which sometimes cause cytotoxicity. The siLuc[S15/RGD]- targeting Renilla luciferase mRNA (Table S3), which contains 15 spermines and a cRGD-peptide, did not silence the expression of RecQL1 mRNA under similar conditions (Figure 4D). Therefore, the RNAi activity of siQL1[S15/RGD], which inhibits RecQL1 mRNA expression, appears to be supported not only by accessory conjugates but also by elaborated RNA sequences. The siQL1[S15] (contains 15 spermines only) did not show gene-silencing activity (Figure $4 \mathrm{E})$. This result indicates that both oligospermine and cRGDpeptide are required for efficient gene silencing. The genesilencing activities of siRNA conjugates were also confirmed by the Western blot analysis (Figure S5).

Next, we evaluated the effects of serum on the silencing activity of siQL1[S15/RGD]. As shown in Figure 4F, the silencing activity of siQL1[S15/RGD] decreased slightly in $2 \%$ fetal bovine serum (FBS) and was eliminated in 10\% FBS conditions. It was reported that intracellular uptake of the cationic oligospermine-siRNA conjugate was inhibited by nonspecific-binding of protein to the siRNA in the serum. ${ }^{21}$ Thus, it is suggested that our siQL1[S15/RGD] also interacted with serum proteins, such that its intercellular uptake was severely reduced.

Cytotoxicity Test. Finally, we examined the cytotoxicity of the siRNA conjugates using siLuc[S15/RGD] because siQL1targeting RecQL1 mRNA has strong antitumor cell activity. A2058 cells were incubated with $125 \mathrm{nM}$ to $1 \mu \mathrm{M}$ of siLuc[S15/ RGD] in serum-free medium. After a $48 \mathrm{~h}$ incubation, cytotoxicity was examined by measuring cell viabilities (Figure 5). Although slight growth inhibition was observed at $1 \mu \mathrm{M}$ of

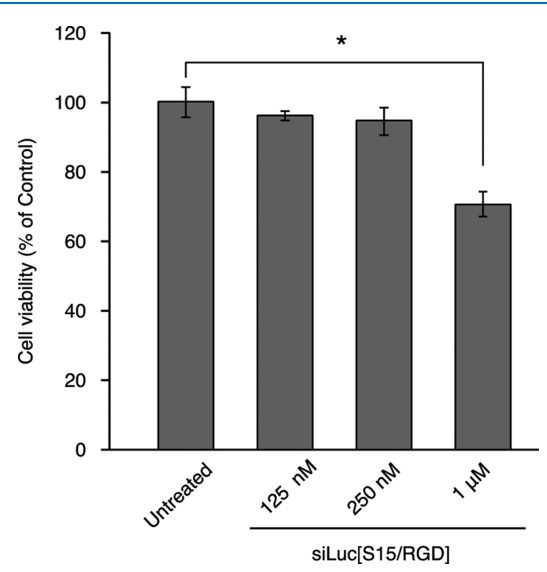

Figure 5. Cell viability at $48 \mathrm{~h}$ after siLuc[S15/RGD] transfection. Cells were transfected with $125 \mathrm{nM}$ to $1 \mu \mathrm{M}$ of siLuc[S15/RGD] without a transfection reagent.

siLuc[S15/RGD], there was no cytotoxicity at $250 \mathrm{nM}$, which is the concentration needed for transfection reagent-free gene silencing of siQL1[S15/RGD]. Although the oligosperminesiRNA conjugates show gene-silencing activities when the N/P ratio is greater than 1.33 , they are sometimes cytotoxic. On the other hand, by incorporating the cRGD peptide into the oligospermine-siRNA conjugate, we succeeded in reducing the
$\mathrm{N} / \mathrm{P}$ ratio to 1.02 to eliminate cytotoxicity while also maintaining the gene-silencing activity.

\section{CONCLUSIONS}

In this study, we successfully synthesized novel cationic oligospermine and cRGD-siRNA conjugates. By combining cRGD peptides with a cationic 15 spermine modification $(\mathrm{N} / \mathrm{P}$ $=1.02)$, we found that $\operatorname{siQL} 1[\mathrm{~S} 15 / \mathrm{RGD}]$ containing both 15 spermines and cRGD peptides showed sufficient gene-silencing activity at $250 \mathrm{nM}$ final concentration without a transfection reagent. Conversely, the siQL1[S15] containing only 15 spermine did not show gene-silencing activity under same conditions. Collectively, these results demonstrate synergy between the oligospermine and cRGD-peptide for efficient gene silencing. It was also found that the siLuc[S15/RGD] caused no cytotoxicity at $250 \mathrm{nM}$, which is the required concentration for transfection reagent-free gene silencing of siQL1[S15/RGD]. Taken together, the oligospermine and cRGD-peptide-combined conjugation holds a great promise for efficient siRNA-mediated drug delivery to various organs and tissues beyond the liver.

\section{EXPERIMENTAL SECTION}

RNA Synthesis. Synthesis was carried out with a DNA/RNA synthesizer by phosphoramidite method. Deprotection of bases and phosphates was performed in concentrated $\mathrm{NH}_{4} \mathrm{OH} / \mathrm{EtOH}$ $(3: 1, \mathrm{v} / \mathrm{v})$ at $55^{\circ} \mathrm{C}$ for $4 \mathrm{~h} .2^{\prime}$-TBDMS groups were removed by TEA.3HF (Aldrich) at $65{ }^{\circ} \mathrm{C}$ for $1.5 \mathrm{~h}$. The reaction was quenched with 0.1 M TEAA buffer ( $\mathrm{pH}$ 7.0) and desalted on a Sep-Pak C18 cartridge. The deprotected ONs were separated from unprotected ONs by $20 \%$ polyacrylamide gel electrophoresis containing $7 \mathrm{M}$ urea to give rise to the highly purified siRNA (Supporting Table).

Postsynthetic Modification of siRNAs Conjugated with CRGD. The cRGD-conjugated antisense strand of RECQL1-siRNA was synthesized by postsynthetic modification method. The cRGD-conjugated antisense RNA strands were purified by reversed-phase C-18 HPLC using a linear gradient of $5-50 \%$ of $\mathrm{MeCN}$ in $0.1 \mathrm{M}$ TEAA buffer at $\mathrm{pH}$ 7.0. The HPLC profiles of synthesized RNA are shown in Figure S4.

Synthesis of siRNAs Conjugated with CRGD at the Antisense RNA 1. To the solution of $6(15 \mathrm{nmol}$ in a total of $100 \mu \mathrm{L}$ ) consisting $10 \mathrm{mM} \mathrm{NaCl}, 100 \mathrm{mM}$ phosphate buffer $(\mathrm{pH} 7.4)(85 \mu \mathrm{L})$, and dimethyl sulfoxide (DMSO) $(15 \mu \mathrm{L}), 0.2$ $\mathrm{M}$ EMCS in DMSO $(12 \mu \mathrm{L})$ was added at the room temperature. The mixture was incubated at $37{ }^{\circ} \mathrm{C}$ overnight and maleimide-modified 8 was collected by RP-HPLC. Subsequently, $50 \mathrm{mM} \mathrm{c}$ (RGDfC) peptide (Bachem) in DMSO $(2 \mu \mathrm{L})$ was added directly to the collected 8 solution. The mixture was then incubated at room temperature overnight and the cRGD-conjugated RNA $1(3.48 \mathrm{nmol})$ was purified by RP-HPLC with a recovery of $23 \%$.

Synthesis of RNA (or ONs) with CRGD Conjugates 2. To the solution of $7(15 \mathrm{nmol}$ in a total of $100 \mu \mathrm{L})$ consisting 10 $\mathrm{mM} \mathrm{NaCl}, 100 \mathrm{mM}$ phosphate buffer $(\mathrm{pH} 7.4)(85 \mu \mathrm{L})$, and DMSO $(15 \mu \mathrm{L}), 0.2 \mathrm{M}$ EMCS in DMSO $(12 \mu \mathrm{L})$ was added at the room temperature. The mixture was incubated at $37{ }^{\circ} \mathrm{C}$ overnight, and maleimide-modified 9 was collected by RPHPLC. Subsequently, $50 \mathrm{mM} \mathrm{c}$ (RGDfC) peptide in DMSO (3 $\mu \mathrm{L})$ was directly added to the collected solution containing 9. The mixture was incubated at room temperature overnight, and 
cRGD-conjugated RNA 2 was purified by RP-HPLC (3.03 nmol, 20\%).

Cellular Uptake Test. A2058 cells $\left(4.0 \times 10^{4}\right.$ cell $\left./ \mathrm{mL}\right)$ were placed on the $35 \mathrm{~mm}$ glass-bottom dish $(200 \mu \mathrm{L} /$ dish $)$ and were grown for $24 \mathrm{~h}$ before transfection. Cells were transfected with $200 \mathrm{nM}$ of Cy3-labeled siRNA conjugates in serum-free OptiMEM medium. After $3 \mathrm{~h}$ of transfection, cells were washed by PBS, and the accumulations of Cy3-labeled siRNA conjugates in the transfected cells were visualized by confocal microscope (Zeiss LSM710).

Gene-Silencing Assay. A2058 cells $\left(4.0 \times 10^{4}\right.$ cell $\left./ \mathrm{mL}\right)$ were transferred to 96 -well plate $(100 \mu \mathrm{L} /$ well $), 24 \mathrm{~h}$ before transfection. Cells were transfected with various concentrations of siRNA conjugates in serum-free Opti-MEM medium. After 4 $\mathrm{h}$ transfection, FBS was added to each well at $2 \%$ final concentration and incubated for $44 \mathrm{~h}$. Cell lysis was performed using SuperPrep Cell Lysis Kit for qPCR (TOYOBO), and RNAs were extracted. Real-time PCR was performed with primers specific for target mRNA by using THUNDERBIRD SYBR qPCR Mix (TOYOBO). The sequences of primer are listed in Table S4.

Cytotoxicity Test. A2058 cells $\left(4.0 \times 10^{4}\right.$ cell $\left./ \mathrm{mL}\right)$ were transferred to a 6-well plate (1 mL/well) $24 \mathrm{~h}$ before transfection. Cells were transfected with various concentrations of siRNA conjugates in serum-free Opti-MEM medium. After 4 $\mathrm{h}$ transfection, FBS was added to each well at $2 \%$ final concentration and further incubation for $44 \mathrm{~h}$. The cell viabilities were determined by the trypan blue dye exclusion test.

\section{ASSOCIATED CONTENT}

\section{S Supporting Information}

The Supporting Information is available free of charge on the ACS Publications website at DOI: 10.1021/acsomega.8b00850.

Experimental procedures, characterizations, and sequences of RNAs and copies of ${ }^{1} \mathrm{H}$ and ${ }^{13} \mathrm{C}$ NMR spectra for compound 12 and ${ }^{31} \mathrm{P}$ NMR spectra for compound 13 (PDF)

\section{AUTHOR INFORMATION}

\section{Corresponding Author}

*E-mail: uenoy@gifu-u.ac.jp. Phone: +81-58-293-2919. Fax: +81-58-293-2919 (Y.U.).

ORCID 8

Yoshihito Ueno: 0000-0003-3492-4677

Notes

The authors declare no competing financial interest.

\section{ACKNOWLEDGMENTS}

This work was supported by Grant-in-Aid for JSPS Research Fellow grant number JP16J03464. This work was also supported by the Japan Agency for Medical Research and Development (AMED) through its Funding Program for Basic Science and Platform Technology Program for Innovative Biological Medicine for the development of siRNA conjugates with tissue-specific delivery functions.

\section{REFERENCES}

(1) Sharma, V. K.; Watts, J. K. Oligonucleotide therapeutics: chemistry, delivery and clinical progress. Future Med. Chem. 2015, 7, 2221-2242.

(2) Crooke, S. T. Molecular Mechanisms of Antisense Oligonucleotides. Nucleic Acid Ther. 2017, 27, 70-77.
(3) Dowdy, S. F. Overcoming cellular barriers for RNA therapeutics. Nat. Biotechnol. 2017, 35, 222-229.

(4) Juliano, R. L. The delivery of therapeutic oligonucleotides. Nucleic Acids Res. 2016, 44, 6518-6548.

(5) Shen, X.; Corey, D. R. Chemistry, mechanism and clinical status of antisense oligonucleotides and duplex RNAs. Nucleic Acids Res. 2017, 46, 1584-1600.

(6) Moschos, S. A.; Jones, S. W.; Perry, M. M.; Williams, A. E.; Erjefalt, J. S.; Turner, J. J.; Barnes, P. J.; Sproat, B. S.; Gait, M. J.; Lindsay, M. A. Lung Delivery Studies Using siRNA Conjugated to TAT(48-60) and Penetratin Reveal Peptide Induced Reduction in Gene Expression and Induction of Innate Immunity. Bioconjugate Chem. 2007, 18, 14501459.

(7) Meyer, M.; Dohmen, C.; Philipp, A.; Kiener, D.; Maiwald, G.; Scheu, C.; Ogris, M.; Wagner, E. Synthesis and Biological Evaluation of a Bioresponsive and Endosomolytic siRNA-Polymer Conjugate. Mol. Pharmaceutics 2009, 6, 752-762.

(8) Ming, X.; Alam, M. R.; Fisher, M.; Yan, Y.; Chen, X.; Juliano, R. L. Intracellular delivery of an antisense oligonucleotide via endocytosis of a G protein-coupled receptor. Nucleic Acids Res. 2010, 38, 6567-6576.

(9) Dohmen, C.; Fröhlich, T.; Lächelt, U.; Röhl, I.; Vornlocher, H.-P.; Hadwiger, P.; Wagner, E. Defined Folate-PEG-siRNA Conjugates for Receptor-specific Gene Silencing. Mol. Ther.-Nucleic Acids 2012, 1, e7.

(10) Willibald, J.; Harder, J.; Sparrer, K.; Conzelmann, K.-K.; Carell, T. Click-Modified Anandamide siRNA Enables Delivery and Gene Silencing in Neuronal and Immune Cells. J. Am. Chem. Soc. 2012, 134, 12330-12333.

(11) Lu, H.; Wang, D.; Kazane, S.; Javahishvili, T.; Tian, F.; Song, F.; Sellers, A.; Barnett, B.; Schultz, P. G. Site-Specific Antibody-Polymer Conjugates for siRNA Delivery. J. Am. Chem. Soc. 2013, 135, 1388513891.

(12) Nikan, M.; Osborn, M. F.; Coles, A. H.; Biscans, A.; Godinho, B. M. D. C.; Haraszti, R. A.; Sapp, E.; Echeverria, D.; DiFiglia, M.; Aronin, N.; Khvorova, A. Synthesis and Evaluation of Parenchymal Retention and Efficacy of a Metabolically Stable O-Phosphocholine-N-docosahexaenoyl-1-serine siRNA Conjugate in Mouse Brain. Bioconjugate Chem. 2017, 28, 1758-1766.

(13) Nair, J. K.; Willoughby, J. L. S.; Chan, A.; Charisse, K.; Alam, M. R.; Wang, Q.; Hoekstra, M.; Kandasamy, P.; Kel'in, A. V.; Milstein, S.; Taneja, N.; O'Shea, J.; Shaikh, S.; Zhang, L.; van der Sluis, R. J.; Jung, M. E.; Akinc, A.; Hutabarat, R.; Kuchimanchi, S.; Fitzgerald, K.; Zimmermann, T.; van Berkel, T. J. C.; Maier, M. A.; Rajeev, K. G.; Manoharan, M. Multivalent N-Acetylgalactosamine-Conjugated siRNA Localizes in Hepatocytes and Elicits Robust RNAi-Mediated Gene Silencing. J. Am. Chem. Soc. 2014, 136, 16958-16961.

(14) Matsuda, S.; Keiser, K.; Nair, J. K.; Charisse, K.; Manoharan, R. M.; Kretschmer, P.; Peng, C. G.; Kel'in, A. V.; Kandasamy, P.; Willoughby, J. L. S.; Liebow, A.; Querbes, W.; Yucius, K.; Nguyen, T.; Milstein, S.; Maier, M. A.; Rajeev, K. G.; Manoharan, M. siRNA Conjugates Carrying Sequentially Assembled Trivalent N-Acetylgalactosamine Linked Through Nucleosides Elicit Robust Gene Silencing In Vivo in Hepatocytes. ACS Chem. Biol. 2015, 10, 1181-1187.

(15) Huang, Y. Preclinical and Clinical Advances of GalNAcDecorated Nucleic Acid Therapeutics. Mol. Ther.-Nucleic Acids 2017, $6,116-132$

(16) Noir, R.; Kotera, M.; Pons, B.; Remy, J.-S.; Behr, J.-P. Oligonucleotide-Oligospermine Conjugates (Zip Nucleic Acids): A Convenient Means of Finely Tuning Hybridization Temperatures. J. Am. Chem. Soc. 2008, 130, 13500-13505.

(17) Paris, C.; Moreau, V.; Deglane, G.; Karim, L.; Couturier, B.; Bonnet, M.-E.; Kedinger, V.; Messmer, M.; Bolcato-Bellemin, A.-L.; Behr, J.-P.; Erbacher, P.; Lenne-Samuel, N. Conjugating Phosphospermines to siRNAs for Improved Stability in Serum, Intracellular Delivery and RNAi-Mediated Gene Silencing. Mol. Pharmaceutics 2012, 9, 3464-3475.

(18) Perche, P.; Nothisen, M.; Bagilet, J.; Behr, J.-P.; Kotera, M.; Remy, J.-S. Cell-penetrating cationic siRNA and lipophilic derivatives efficient at nanomolar concentrations in the presence of serum and albumin. J. Controlled Release 2013, 170, 92-98. 
(19) Nothisen, M.; Bagilet, J.; Behr, J.-P.; Remy, J.-S.; Kotera, M. Structure Tuning of Cationic Oligospermine-siRNA Conjugates for Carrier-Free Gene Silencing. Mol. Pharmaceutics 2016, 13, 2718-2728.

(20) Gagnon, K. T.; Watts, J. K.; Pendergraff, H. M.; Montaillier, C.; Thai, D.; Potier, P.; Corey, D. R. Antisense and Antigene Inhibition of Gene Expression by Cell-Permeable Oligonucleotide-Oligospermine Conjugates. J. Am. Chem. Soc. 2011, 133, 8404-8407.

(21) Danhier, F.; Le Breton, A.; Préat, V. RGD-Based Strategies To Target Alpha(v) Beta(3) Integrin in Cancer Therapy and Diagnosis. Mol. Pharmaceutics 2012, 9, 2961-2973.

(22) Alam, M. R.; Ming, X.; Fisher, M.; Lackey, J. G.; Rajeev, K. G.; Manoharan, M.; Juliano, R. L. Multivalent Cyclic RGD Conjugates for Targeted Delivery of Small Interfering RNA. Bioconjugate Chem. 2011, $22,1673-1681$.

(23) Liu, X.; Wang, W.; Samarsky, D.; Liu, L.; Xu, Q.; Zhang, W.; Zhu, G.; Wu, P.; Zuo, X.; Deng, H.; Zhang, J.; Wu, Z.; Chen, X.; Zhao, L.; Qiu, Z.; Zhang, Z.; Zeng, Q.; Yang, W.; Zhang, B.; Ji, A. Tumor-targeted in vivo gene silencing via systemic delivery of cRGD-conjugated siRNA. Nucleic Acids Res. 2014, 42, 11805-11817.

(24) Futami, K.; Kumagai, E.; Makino, H.; Goto, H.; Takagi, M.; Shimamoto, A.; Furuichi, Y. Induction of mitotic cell death in cancer cells by small interference RNA suppressing the expression of RecQL1 helicase. Cancer Sci. 2008, 99, 71-80.

(25) Futami, K.; Kumagai, E.; Makino, H.; Sato, A.; Takagi, M.; Shimamoto, A.; Furuichi, Y. Anticancer activity of RecQL1 helicase siRNA in mouse xenograft models. Cancer Sci. 2008, 99, 1227-1236.

(26) (a) Judge, A. D.; Bola, G.; Lee, A. C. H.; MacLachlan, I. Design of noninflammatory synthetic siRNA mediating potent gene silencing in vivo. Mol. Ther. 2006, 13, 494-505. (b) Robbins, M.; Judge, A.; Liang, L.; McClintock, K.; Yaworski, E.; MacLachlan, I. 2'-O-methyl-modified RNAs Act as TLR7 Antagonists. Mol. Ther. 2007, 15, 1663-1669.

(27) Voirin, E.; Behr, J.-P.; Kotera, M. Versatile synthesis of oligodeoxyribonucleotide-oligospermine conjugates. Nat. Protoc. 2007, 2, 1360-1367. 